\title{
Da proto-performance ao espetáculo: fronteiras nebulosas
}

\author{
Carlos Ataíde
}

$\checkmark \sqrt{3}$ oje, vivenciamos no teatro uma crise confirmada pela desconfiança generalizada de como observamos e temos discutido a relação entre a representação teatral e sua ligação com o mundo, surgindo, por toda parte, questóes sobre a natureza do teatral e do real, sobre a pertinência da representação e sobre a condição da personagem. Questôes estas que também foram alvos constantes de análises teóricas e/ou práticas durante todo o processo de construção da proto-performance $O$ Álbum (janeiro de 2007) até a concepção final e primeira temporada (de junho a novembro de 2009, em São Paulo) do espetáculo Memória da Cana.

O Álbum, como a princípio era chamado pelo seu autor Newton Moreno, tinha a vocação/curiosidade de investigar a família brasileira, microcosmo das relaçôes de poder da nossa sociedade. Uma aproximação, uma tentativa de interpretar quem somos através do estudo matricial da constituição desta família. Era uma investigação espetacular (a princípio, uma proto-performance) a partir de Álbum de Família, de Nelson Rodrigues, alimentada pela leitura de textos basilares sobre a formação da família brasileira, dentre eles Casa grande \& Senzala, de Gilberto Freyre, bem como do esquadrinhamento das árvores genealógicas dos atores de origem nordestina/pernambucana participantes do processo. Era o desejo de devolver O Álbum a Recife, devolver um pouco de Nelson à sua origem. Tínhamos ciência que estávamos sendo conduzidos, com Nelson, ao (re)encontro de nossas origens. Apenas não suspeitávamos que elas fossem tão surpreendentes e profundamente reveladoras de nós mesmos.

Ao iniciar os trabalhos d'O Álbum, minha realidade no processo era a de ator recifense, radicado em São Paulo há 15 anos, componente do grupo Os Fofos Encenam, convocado a colocar à disposição suas histórias pessoais familiares a serviço da concepção de uma protoperformance, em que não havia, a priori, uma dramaturgia textual ou cênica, nem personagens ou personas ou figuras. Muitas questōes surgiram desse desafio, como, por exemplo, encontrar a forma de conduzir a criação das personas ou $f_{i-}$ guras ou personagens que viessem a surgir dos procedimentos e provocaçóes de Newton Moreno. Como essa realidade tão pessoal e íntima poderia alcançar o espectador?

Algumas respostas pareciam surgir a partir dos procedimentos para a construção da cena, propostos por Moreno, e que foram revelando, a meu ver, uma forte aproximação do diretor, dramaturgo e ator com a arte da perfor-

Carlos Ataíde é ator do grupo "Os fofos encenam". 
mance ${ }^{1}$. Inferência que faço a partir de suas escolhas para a elaboração da investigação espetacular, constituída de quatro etapas. A primeira era a construção de duas figuras ${ }^{2}$ a partir de fotos escolhidas por cada ator em um trabalho prático com o ator do Lume e professor Renato Ferracini: uma seria construída partindo-se de uma foto de criança ou bebê e outra de uma foto de um idoso da família. Um começo de trabalho em busca de nossas origens e idiossincrasias mais que genuíno. Inicialmente, não existiam textos, nem nomes, nem relações entre as figuras. Estes foram aparecendo gradualmente, a partir dos jogos de improvisação sugeridos por Ferracini. Também gradualmente, uma das $f-$ guras foi prevalecendo diante da outra, até firmar-se definitivamente. Em meu processo, por exemplo, sobressaiu-se a figura do bebê e uma relação forte com a figura da "velha" criada pela atriz Luciana Lyra. As relações eram genéricas, pois não havia distinção de idade, parentesco ou gênero.

A construção de figuras continuou na segunda e terceira etapas do processo de criação proposto por Moreno. Na segunda etapa aconteceu a elaboração de narrativas pessoais a partir de nosso contexto familiar - uma primeira narrativa pessoal era feita apenas com imagens, uma segunda com predominância da palavra, enquanto a última ficava a critério do ator-criador, ou seja, todos os atores participantes do processo.

Nesse momento do trabalho, a tônica de minhas ações eram as relações com meus pais e meus avós paternos. Na sequência, quando pas- samos à feitura de situaçóes/cenas/improvisos em torno do tema "família", que deveriam ser desenvolvidos a partir da obra Casa-Grande \& Senzala, de Gilberto Freyre, foram ressaltados, nas cenas que criei, os elementos negros e índios de minha ancestralidade.

$\mathrm{Na}$ quarta e última etapa dessa investigação veio o texto de Nelson Rodrigues, o Álbum de Familia, e com ele, os personagens para dialogar e cruzar com as figuras e as situaçōes levantadas nas três etapas anteriores, na definição da dramaturgia textual e cênica. A mim me coube a "miscigenação" da figura da primeira etapa do processo, da foto-bebê, com o personagem rodrigueano Edmundo, além da amalgamação de uma das figuras surgidas na terceira etapa, Freyre, com outro personagem rodrigueano, Nonô. Essa foi a etapa mais delicada e mais áspera de todo o processo. Um momento de fricção e trânsito entre o nosso "eu", os nossos outros "eus" construídos até então e um outro "eu" até então "desconhecido": o do personagem rodrigueano. Mecanismos de introjeção e de projeção se instauraram e embaralharam nossas subjetividades e alteridades. Os limites entre o "eu" e o "outro" ficaram ininteligíveis e aproximaçōes, afastamentos e abandonos nem sempre confortáveis e prazerosos, porém inevitáveis e imprescindíveis, foram requeridos nesse momento. Vida e arte se confundiam e nos confundiam. Porém, o trabalho cênico com figuras construídas pelo ator procurava evitar qualquer confusão entre a arte e a realidade, pois, segundo Jean-Pierre Sarrazac,

1 [...] no uso mais geral, performance se refere de modo imediato a um acontecimento oral e gestual.[...] [Na] noção de performance, [há] sempre um elemento irredutível, a idéia da presença de um corpo. Recorrer à noção de performance implica então a necessidade de reintroduzir a consideração do corpo no estudo da obra.[...] o comprometimento empírico, agora e neste momento, da integridade de um ser particular numa situação dada (Zumthor, 2000, p. 45).

2 Caracterizo aqui figura como esta nos é apresentada por Sarrazac (2002, p. 109, grifo do autor): “[...] lugar de conflagração do individual e do coletivo, corpo único no qual uma comunidade delega vozes, socializa a personagem. A figura aprofunda a personagem [...] desdobra-se numa personagem plural. E, ao mesmo tempo, afasta o espectador da contemplação mórbida de um destino individual [...]" 
[...] [a] presença teimosa do corpo proíbe qualquer fuga para a abstração ou para o céu das alegorias. A figura não representa, portanto, nem a hipóstase nem a dissolução, mas um novo estatuto da personagem dramática: personagem incompleta e discordante que se dirige ao espectador para ganhar forma; personagem a construir (Sarrazac, 2002, p. 107-8, grifo do autor).

Neste procedimento, o corpo do ator é seu próprio signo, é a matriz da peça de arte, como também o é na performance. E mais: o espectador é participante ativo do processo cênico, inclusive na construção dessas personagens/figuras.

Além de Sarrazac, também Renato Cohen admite que, no teatro contemporâneo, o termo figuras seja mais apropriado que personagens. Porém, prefere utilizar o termo persona, que "[...] diz respeito a algo mais universal, arquetípico. [...] A persona é uma galeria de personagens. [...] O trabalho do performer é de 'levantar' sua persona" [...] (Cohen, 2004, p. 106-8; grifos do autor).

Em meu processo criativo de ator, eu poderia afirmar que desenvolvo um trabalho de performer, pois procuro criar uma galeria de personas/personagens a partir de idiossincrasias, habilidades e memórias pessoais. Portanto, neste caso, "não se encara a atuação como uma profissão, mas como um palco de experiência ou de tomada de consciência para utilização na vida. Nele não vai existir uma separação rígida entre arte e vida” (Cohen, 2004, p. 104).

Foram, e são, a memória e a imaginação as grandes propulsoras de nossa criação. Ambas, somadas à criatividade e à inspiração, e ao vasculhar de nosso consciente e subconsciente, foram capazes de nos fazer "passar" por outro para "chegarmos" a nós mesmos, em um processo de individuação, para só depois retornar a "uma nova personalidade". Um escarafunchar, por vezes, doloroso, incômodo, e até, cruel, pois
A memória assemelha-se às antigas mesas de costura. Possui gavetas pequeninas e secretas, algumas fechadas há tantos anos que se tornam perras e difíceis de abrir. Contêm flores secas que, com o tempo, formam apenas uma poeira de pétalas. Retroses embaraçados, carretéis vazios, agulhas enferrujadas e alguns alfinetes podem ferir mãos pouco avisadas. Essa memória, trajada de escaninhos abandonados, [estimulou-nos] a sacolejá-la. Com a finalidade de clarear os lampióes quase apagados da lembrança, aviva traços escurecidos, revela zonas obscuras, instiga um recordar que tem pulsões catárticas. Envolve-se com um passado que vai se despindo num processo permanente de desvelamento. $\mathrm{O}$ foco se centraliza na [nossa família]. Mistérios, sigilos, segredos. Bisbilhotices, por que não? [...] (Quintas, p. 271).

A memória de nosso núcleo familiar mais próximo (e a mais distante que pudemos alcançar), foi nossa principal fonte criadora para esse processo. Foi capaz de acionar nossa imaginação e possibilitar a recordação de imagens, pessoas, acontecimentos, numa exploração do subconsciente que atravessava nosso corpo e tinha o corpo como cerne do processo criativo, permitindo assim recriá-los e torná-los menos abstratos e mais próximos de uma representação sensível. Temos aqui o que Grotowski e Barba chamam de memória corporal. Grotowski afirma que é a partir da memória, tanto corporal quanto mental, que o ator, na fase dos ensaios, pode criar a tessitura da interpretação, adicionando ao papel escrito o desdobramento exacerbado de sua personalidade, revestindo-o com as fibras de sua vida passada e presente (Aslan, 2005). É exatamente assim que poderia expressar, em palavras, nosso processo de criação desses seres ficcionais, amálgama de figuras e personagens. É também partindo da memória corporal que Eugenio Barba, como nós nesse processo, busca construir um "novo corpo", diferente do cotidiano a ponto de ser capaz de criar uma relação 
cinestésica com o espectador. Barba afirma que o corpo do ator cria ações geradas por impulsos interiores que fluem porque estão enraizados em sua memória corporal (Azevedo, 2004).

Nessa forma de comunicação teatral, a presença corporal do intérprete, e também do espectador, são presenças plenas, em vigília, carregadas de poderes sensoriais. Aqui, como na arte da performance, a comunicação não se liga apenas ao corpo, mas, por meio deste, ao espaço.

O espaço cênico é uma referência forte que, por si só, é mais uma das narrativas que coexistem no Album e em Memória da Cana. Ele foi criado de forma concomitante às ações propostas, pois concebíamos nossos próprios espaços cênicos durante o processo criativo, sempre pensando na pluralidade dos sentidos e na possibilidade de os espaços terem cheiro, cor e volume, mas sempre guiados por uma preocupação primordial: a relação com o espectador.

O espaço/corpo do ator/corpo do espectador forma uma tríade que marca solidamente e sensivelmente Álbum e Memória da Cana. Pois o espaço desse trabalho não representa apenas um lugar físico, mas também um lugar psicológico e filosófico, um lugar para o qual Renato Cohen, na performance, utiliza o termo topos, que bem no caso de nossa criação, pois é

nesse topos que se [dão] as relaçôes entre os dois pólos definidos da expressão cênica (atuantes-público). Essas relações [ocorrem] através de um "texto", por intermédio do qual [acontecem] todas as transposições características da arte (passagem da vida para a representação, do real para o imaginário e o sim- bólico, do inconsciente para o consciente etc.)

(Cohen, 2004, p. 116, grifo do autor).

Em nosso caso, portanto, a relação com o público é capital, assim como o é para a performance. É a partir dessa relação entre espectador e ator, e da idéia de topos, que poderia afirmar que tanto Álbum como Memória da Cana são modelos míticos de encenação, característicos da performance (Cohen, 2004), através dos quais se estabelece a participação do espectador, não necessariamente por sua ação física. Pois do ponto de vista psicológico, ele é participante, oficiante e não simplesmente espectador.

Esse modelo mítico de encenação ou "teatro mítico", "[...] geralmente não [acontece] em edifícios-teatro. Ele se dá em praças, galpões, campanários, etc., como os espaços sugeridos por Artaud para seu 'teatro sagrado"' (Cohen, 2004, p. 128). Álbum e Memória da Cana não foram concebidos para edifícios-teatro, rompendo, assim, as fronteiras espaciais do modelo estético clássico do teatro.

O teatro realizado por Moreno n' Os Fofos Encenam é uma "emergência", uma necessidade: um fenômeno que sai do contexto cultural e situacional, ao mesmo tempo em que nele encontra lugar, como acontece com a performance, em que vida e arte miscigenam-se. Vou aqui denominá-lo teatro de fronteira ou teatro pós-dramático, por se referir, no dizer de Zumthor (2000), a um acontecimento oral e gestual em que há um elemento irredutível, que não é o texto, mas o corpo do ator e sua relação com o espaço, condição necessária à criação da teatralidade 3 .

3 Teatralidade "é o teatro menos o texto, é uma espessura de signos e de sensações que se edifica no palco a partir do argumento escrito" (Roland Barthes apud Stalloni, 2007, p. 48). Outro conceito de teatralidade quem nos dá é Abirached (1994, p. 192) Lo teatral, en su especificidad, no tiene nada que ver con los caracteres que le atribuye la opinión común: ni enfático ni relumbrón ni imitativo, es de una naturaleza esencialmente visusal. Sustituye la idea por la imagen em movimiento, en um espacio estructurado em si mismo; prefiere la impresión producida por el juego de las formas a la palabra [...] su facultad principal es la imaginación [...] y cuyo modo de expresión superior es el símbolo. 
Teatralidade que tem por principal característica a imaginação, qualidade sem a qual não se pode ser ator, pois é ela quem desperta a sensibilidade e promove a frutífera relação com o espaço e com o "outro", o personagem, com sua realidade imediata e mediata, mas que se configura pela imediatez, velocidade e urgência de uma era marcada pelo discurso da ciência, que interfere e modifica a relação do ator com o personagem. Entretanto,

O importante para quem quer extrair a verdade de um ser e, a fortiori, definir as coordenadas de um personagem capaz de expressar esta verdade, é ir ao encontro do núcleo primitivo da sua consciência e descobrir o momento crucial em que seu destino tomou a direção decisiva [...] $\mathrm{O}$ autor encontrará também em sua própria historia os esquemas primitivos do drama de todos os homens e alimentará a biografia de suas personagens com sua autobiografia: o que pode mostrar é o mundo capturado através de seu olhar e reconstruído no espelho ordenador de seus fantasmas; para erigir o universo objetivo que reclama o cenário não pode fazer outra coisa mais que submergir no mais profundo de sua subjetividade (Abirached, 1994, p. 198). ${ }^{4}$

E, finalmente, é interessante investigar se um espetáculo construído a partir da somatória de particularidades individuais e familiares específicas de um contexto sócio-econômico-cultural, e com alto grau de subjetividade, é capaz de provocar curiosidade e movimento no espectador. Em crítica do espetáculo, Celso Curi (2009, p. 26) oferece algumas pistas: "[Memória da Cana é] um santuário-instalação da brasilidade e da família [...] [que facilita] o voyeurismo para dentro de nós mesmos".

4 Lo importante, para quien quiere extraer la verdad de um ser y, a fortiori, definir las coordenadas de um personaje capaz de expresar esta verdad, es ir al encuentro del núcleo primigenio de su conciencia y descubrir el momento crucial en que su destino tomó la dirección decisiva [...]. El autor encontrará también em su propria historia los esquemas primitivos del drama de todos los hombres y alimentará la biografia de sus personajes com su autobiografia: lo que puede mostrar es el mundo captado a través de su mirada y reconstruido en el espejo ordenador de sus fantasmas; para erigir el universo objetivo que reclama el escenario no puede hacer otra cosa más que submegirse en lo más profundo de su subjetividad (Abirached, 1994, p. 198). 


\section{Referências bibliográficas}

ABIRACHED, Robert. La crisis del personaje en el teatro moderno. Traducción de Borja Ortiz de Gondra. Madrid: Publicacions de la Asociacion de Directores de Escena de Espanña. Série: Teoria y Práctica del Teatro No 8. 1994, p. 167-233.

ASLAN, Odette. O Ator no século XX: evolução da técnica, problema da ética. Tradução de Rachel Araújo de Baptista Fuser, Fausto Fuser e J. Guinsburg. São Paulo: Perspectiva. 2005. p. 279305.

AZEVEDO, Sônia Machado de. O Papel do Corpo no corpo do ator. São Paulo: Perspectiva, 2004, p. 3-49.

COHEN, Renato. Performance como linguagem: criação de um tempo-espaço de experimentação. $2^{a}$ edição. São Paulo: Perspectiva, 2004.

CURI, Celso. Eu como você. In: Brasileiros. São Paulo: Brasileiros Editora Ltda. Número 25; ago/ 2009, p. 26-7.

DIDEROT, Denis. Discurso sobre a poesia dramática. Tradução, organização, apresentação e notas: Franklin de Mattos. São Paulo: Cosac Naify, 2005.

. Paradoxo Sobre o Comediante. In: Diderot: Textos Escolhidos. Tradução Marilena Souza Chauí, J. Guinsburg. São Paulo: Abril Cultural, 1979.

QUINTAS, Fátima. Memória e tempos pretéritos: fantasmas e assombrações da casa-grande. Cópia xerox.

SARRAZAC, Jean-Pierre. O futuro do drama. Porto: Campo das Letras, 2002, p. 94-129.

STALLONI, Yves. Os gêneros literários. Tradução e notas Flávia Nascimento. Rio de Janeiro: DIFEL, 2007.

ZUMTHOR, Paul. Performance, percepção, leitura. Tradução: Jerusa Pires Ferreira, Suely Fenerich. São Paulo: EDUC, 2000. 


\section{Bodas de Sinhá: processo de f(r)icção sob a máscara ritual de Dona Senhorinha}

A casa, o corredor... No longo caminho de finas $e$ delicadas transparências, anuviada nubente. Alva, clara como a luz que alumia o caminho. Claros sons de tambores em maracatu anunciam o ritual. Olhos em luto choram a passagem na marcha compassada nupcial. É Sinhá, Dona Sinhá! Altiva, rainha de uma corte familiar. Dona, silenciosa está. Antigos odores de gaveta são também seus guias. Fátima é condutora. Nossa senhora branca, branca. Ao fim do cortejo, sob naftalina chuva, um recanto de memórias do que já foi. Mãe, avós em fotografias espalhadas. A mesa e sua branca toalha. Olhos esquivos, óculos de Santa Luzia. Num badalo... O TEMPO... Um desnudamento. Corpo rubro desleva-se. Aborto de lembranças, dos tantos filhos que encantou e se perderam em canaviais. No corpo nu em banquete, a audiência constrói a árvore de nomes passados. No chão de terra, sinhá vai gerar o novo. Vai niná-lo ao som de familiares vozes. Vozes meninas, vozes avós. Imagens meninas, imagens avós.

scrito no dia 03 de abril de 2008, o texto acima aponta, mesmo que brevemente, as camadas imagéticas pelas quais fui transpassada no processo de criação da figura de Dona Senhorinha, no espetáculo Memó-
Luciana Lyra

ria da Cana, dirigido por Newton Moreno e realizado pela Companhia Os Fofos Encenam.

Acometida por imagens das matriarcas de minha família, das sinhás das casas-grandes e dos sobrados relatadas por Gilberto Freyre, assim como da Senhorinha da dramaturgia de Nelson Rodrigues, corporifico uma figura, que por trazer forte carga memorial, procura romper com a representação, aproximando-se de um alto grau de pessoalidade. Sob a égide do que chamo aqui de máscara ritual de Sinhá, descortino um trajeto pessoal, na restauração de minha própria história como parte de uma história familiar antepassada.

$\mathrm{O}$ processo de construção de Dona Senhorinha deu-se em três fases. Por orientação da direção, a fase primeira configurou-se a partir da criação de cena não-verbal, de onde se originou a figura que chamei de noiva enlutada. Vestida de noiva, estampando grandes óculos escuros, percorria dançando um corredor de paredes transparentes ao som de uma bricolagem da marcha nupcial com o som do maracatu de corte. A cena desembocava em nudez encharcada de sangue, articulando imagens de casamento familiares à decadência da idéia do matrimônio. A cena simbolizava um luto meu quanto à idéia do casamento.

Luciana Lyra é atriz da companhia Os fofos encenam. 
Numa segunda fase, que teve como mola propulsora a oficina do professor Renato Ferracini, a noiva enlutada desdobrou-se no arquétipo da mãe extremosa. Partindo de uma fotografia pessoal, construí movimentos corporais com braços e mãos, que traziam ainda o maracatu, mas estavam num constante chamamento ao colo, um percorrer do espaço à procura do acolhimento. Uma canção de ninar constante embalava a movimentação da figura. Com a mãe extremada desenvolvi cenas verbalizadas, estabeleci contato com outros atuantes em jogos cênicos e pude ainda desdobrá-la em terceira figura: Sinhá Dona Sinhá. Proveniente de impulsos imagéticos da obra de Gilberto Freyre, Sinhá Dona Sinhá trazia à tona o poder velado da mãe, a voz dominadora e a extraordinária capacidade de ação matriarcal que se exercia na autoridade do gesto.

A terceira e última fase de construção desvelou-se, justamente, na intersecção entre a Noiva Enlutada, a Mãe Extremosa, Sinhá Dona Sinha e, enfim, a Dona Senhorinha rodrigueana. Talvez esta tenha sido a mais complexa etapa, na medida em que cenas e imagens levantadas por intermédio da memória pessoal e impulsos de jogos cênicos iam ao encontro de uma personagem de estrutura dramatúrgica pré- estabelecida. Nesta fase, os arquétipos apontados durante o processo embasaram e deram a tônica do preenchimento da personagem dramatúrgica, gerando um estado híbrido entre pessoal e ficcional.

Ao visualizar esta trajetória, percebo que o processo de atuação em Memória da Cana está calcado na ritualização das idiossincrasias dos atuantes, em detrimento da interpretação de qualquer papel. Ao vivenciar Dona Senhorinha, não me entendo personagem mas, como aponta o diretor norte-americano Richard Schechner
(2002), "não-não o personagem". Também não sou eu mesma, mas "não-não eu mesma". Entendo-me como um corpo que se multiplica na subjetividade, tornando-se ponto de passagem de diferentes estados e energias, que o atravessam sem jamais cristalizar-se num único significado ou representação. Desta maneira, nos interstícios entre eu e a persona, meu corpo adentra em constantes fluxos de memórias, revelando uma máscara ritual de mim mesma.

A experiência em Memória da Cana provoca mais do que um simples espelhamento do real. Trata-se de um processo de espelhamento interativo e matricial, diz o antropólogo Victor Turner(1982). Se como "espelhos mágicos" dramas estéticos e rituais espelham a vida, a recíproca também é verdadeira: a vida pode espelhar formas estéticas. Pessoas que se revelam como personas performatizam suas vidas.

Partindo destas proposiçóes, concluo que na atuação liminar sob a máscara ritual de $S e$ nhorinha gera-se um estado de $f(r) i c ̧ c a ̃ o$, de atrito e desconstrução que é dialeticamente inverso ao da ficção (fictio ou algo modelado, construido) (DAWSEY, 2000), que se revela na experiência da performance teatral, onde imagens do passado se articulam ao presente.

Durante a temporada de Memória da Cana, espetacularizo as matriarcas de minha família. As fotografias de minha mãe-noiva são restauradas pelo meu corpo em ação cênica, os óculos de minha avó materna são emprestados à aparente fragilidade de D. Senhorinha, as memórias ganham o centro da cena, na re-afirmação da história pessoal em diálogo direto com a história cultural. Alimento-me da máscara de Senhorinha, oferecendo a esta mesma máscara, pelo caminho inverso, a possibilidade da restauração pela experiência performática. 


\section{Referências bibliográficas}

DAWSEY, John. Victor Turner e a antropologia da experiência. São Paulo. Cadernos de Campo, 13, p. 110-21, 2005.

SCHECHNER, Richard. Performance studies - an introduction. London e New York. Routledge, 2002.

TURNER, Victor. From Ritual to Theatre. New York. PAJ, 1982. 